\title{
Humor Apto Todo Público. El cine de entretenimiento de Alberto Olmedo, Jorge Porcel y Enrique Carreras
}

\author{
PG Humor. The entertainment cinema of Alberto Olmedo, Jorge \\ Porcel and Enrique Carreras
}

\begin{abstract}
Fabio Nicolás Fidanza fabiofidanza26@gmail.com
https://orcid.org/0000-0002-5568-0176

Instituto de Historia del Arte Argentino y Latinoamericano "Luis Ordaz"; Facultad de Filosofía y Letras; Universidad de Buenos Aires (Argentina)
\end{abstract}

\section{Resumen}

Los actores cómicos, Alberto Olmedo y Jorge Porcel, desarrollaron una extensa carrera que abarcó diversos medios y expresiones artísticas. Entre 1973 y 1988 la dupla realizó más de treinta películas para la productora Aries Cinematográfica. Si bien todas las películas que 
protagonizaron pueden considerarse comedias, no todas responden a las mismas características. A lo largo de sus carreras su obra fue transformándose, dando origen a distintas variantes textuales. El objetivo de este trabajo es analizar las transformaciones que se dieron en los filmes protagonizados por esta dupla de cómicos, tanto a nivel textual como argumental, con el fin de dar cuenta del proceso de adecuación que llevó a cabo el dúo para responder a las necesidades de cada época. Analizaremos el tipo de humor que proponen estas comedias, así como también los personajes prototípicos y los roles de género que las películas proponen, y la relación que estas comedias tienen con la industria del entretenimiento nacional.

Palabras clave: Humor; cine argentino; sociedad argentina.

\section{Abstract}

The comedians, Alberto Olmedo and Jorge Porcel, developed an extensive career in the entertainment industry. Between 1973 and 1988 the duo made more than thirty films for Aries Cinematográfica studio. Even though all the films that the duo starred in can be considered comedies, not all respond to the same characteristics. Throughout their careers their work went trough several changes creating different textual variants. The aim of this work is to analyze the transformations in the films starred in by this comedians, both at the textual and at the plot level, in order to give an account of the process of adaptation that the duo carried out to respond to the needs of each era. We will analyze the type of humor proposed by these comedies, as well as the prototypical characters and gender roles that this films propose, and also the relationship that these comedies have with the national entertainment industry.

Keywords: Humor; argentine cinema; argentine society.

Los actores cómicos, Alberto Olmedo y Jorge Porcel, desarrollaron una extensa carrera que abarcó diversos medios y expresiones artísticas -como la radio, la televisión, el teatro y el cine-, llegando a conformar uno de los dúos cómicos más populares de la industria del entretenimiento en Argentina. Entre 1973 y 1988 -año del fallecimiento de Olmedo- la dupla realizó más de treinta películas para la productora Aries Cinematográfica. Si bien todas las películas que protagonizaron pueden considerarse comedias, no todas responden a las 
mismas características. A lo largo de sus carreras su obra fue transformándose dando origen a distintas variantes textuales. Entre 1973 y 1982, Olmedo y Porcel, se movieron dentro de la denominada comedia picaresca, un cine destinado al público adulto que proponía un humor centrado en lo sexual y lo escatológico. Sin embargo, a partir de 1982 la dupla comenzó a incursionar en un ámbito hasta ese momento casi inexplorado por ambos cómicos, el del entretenimiento familiar. Estos cambios se dieron de la mano del productor y director Enrique Carreras, quien tenía una amplia trayectoria en el campo cinematográfico local y era conocido por su capacidad para realizar productos familiares exitosos.

Para entender estas transformaciones es necesario tener en cuenta la propuesta de trabajo desarrollada por Geoff King (2002) para el análisis de la comedia. A diferencia de gran parte de quienes la abordaron como un género, este teórico propone entender a la comedia como un modo, es decir, como una forma de abordar un material. A su vez destaca que debe ser analizada siempre en relación con sus contextos, tanto en su producción, su representación, como en las expectativas y presupuestos del receptor. A medida que las sociedades van cambiando y los paradigmas sociales se modifican, la comedia se adecúa a los mismos para responder a las demandas del público. Entendemos que dentro de la filmografía de Olmedo y Porcel pueden encontrarse diversos tipos de comedias, cada una con características singulares, determinadas por cuestiones relacionadas al devenir de la comedia, a las transformaciones del campo cinematográfico y a las del país.

También es necesario tener en cuenta el análisis de Raymond Williams (1981) en relación a las dinámicas de la producción cultural. Este autor entiende que la cultura funciona como un espacio fluctuante en el que coexisten distintas variantes representacionales que ocupan estratos diferentes dentro del campo cultural. Consideramos que esta propuesta es aplicable al ámbito de la comedia cinematográfica y nos permite pensar que, si bien al interior de la misma conviven distintas propuestas, hay modelos que pueden convertirse en hegemónicos durante determinados períodos y luego, producto de las transformaciones al interior del campo, perder ese lugar. En este sentido, entendemos que el modelo de la comedia picaresca fue una modalidad cómica dominante en la Argentina durante los setenta y que hacia comienzos de los ochenta el campo de la comedia, en consonancia con las profundas modificaciones políticas y culturales, se reconfiguró dando lugar a la emergencia de nuevos modelos como el propuesto por la comedia de entretenimiento familiar.

En función de estas ideas, el objetivo de este trabajo es analizar las transformaciones que se dieron en los filmes protagonizados por esta dupla de cómicos, tanto a nivel textual como argumental, con el fin de dar cuenta del proceso de adecuación que llevó a cabo el dúo para responder a las necesidades de cada época. Para ello tendremos en cuenta las

Question, Vol. 1, N. ${ }^{\circ}$ 63, julio-septiembre 2019. ISSN 1669-6581

Instituto de Investigaciones en Comunicación | Facultad de Periodismo y Comunicación Social | Universidad Nacional de La Plata La Plata | Buenos Aires | Argentina

Página 3 de 19 
particularidades de la comedia producida por Aries Cinematográfica, la trayectoria de ambos comediantes y de Enrique Carreras, tanto en el cine como en otros ámbitos del espectáculo argentino, a la vez que el contexto social y político del país en que se dieron estas modificaciones. Analizaremos el tipo de humor que proponen ambos modelos -la comedia picaresca y la comedia de entretenimiento familiar-, así como también los personajes prototípicos y los roles de género que los mencionados subgéneros proponen, y la relación que estas comedias tienen con la industria del entretenimiento nacional.

\section{De los hermanos Sofovich a Enrique Carreras}

La llegada de Olmedo y Porcel a Aries, en 1973, se dio como resultado de un arreglo comercial entre los dueños de la productora -Fernando Ayala y Héctor Olivera- y un nuevo grupo de socios: el productor Nicolás Carreras y los hermanos Gerardo y Hugo Sofovich. La idea de realizar una comedia para adultos con el dúo cómico como protagonistas partió de Carreras y de los hermanos Sofovich y entusiasmó a los dueños de Aries, quienes estaban interesados en producir un cine masivo y redituable que les permitiera solventar los gastos que implicaba el mantenimiento de los recientemente adquiridos estudios Baires (López, 2005). El primer filme protagonizado por los comediantes, Los caballeros de la cama redonda (Gerardo Sofovich, 1973), tuvo un éxito rotundo por lo que la sociedad decidió encarar nuevas producciones que resultaron igual de exitosas. La conjunción del humor pasatista y subido de tono de Olmedo y Porcel y los desnudos de vedettes populares resultó ser una fórmula taquillera. Dado el éxito del modelo propuesto por Aries este comenzó a ser imitado por otras productoras (1). Esto generó que la comedia picaresca se convirtiera en un modelo cultural hegemónico durante el último gobierno militar (2).

Para comienzos de los ochenta, el modelo que Aries había propuesto para sus estrellas comenzó a mostrar señales de agotamiento. Para dicho período la industria cinematográfica, al igual que el país, se encontraba en crisis. La economía se desplomaba producto del fracaso de la política financiera de Martínez de Hoz generando un estancamiento en la producción cinematográfica, la disminución de estrenos nacionales y un aumento en el precio de las entradas que generó el alejamiento de las clases populares de los cines (Getino, 1998; Invernizzi y Gociol, 2006). Si bien las productoras lograban recuperar lo invertido gracias al aumento exorbitante del valor las localidades era claro que el alejamiento de las salas de un número importante del público era perjudicial para la pequeña industria local. 
Al mismo tiempo se comenzaba a producir un cine distinto al del modelo que imperó durante la última dictadura. Gracias a la apertura que se produjo durante la transición hacia la democracia, la producción del período pudo abordar temas silenciados en el cine del período dictatorial y propuso nuevas formas para retratar algunos de los temas presentes en las películas de la dictadura (3). Al mismo tiempo que se producía un cine que buscaba repensar el pasado reciente, la pequeña industria, a tono con el "destape" comenzó a producir películas en donde el sexo y la violencia eran moneda corriente. La comedia picaresca de Olmedo y Porcel, ya no solo tenía competidores que imitaban su modelo, sino que ahora debía competir con un cine que, encuadrado dentro del exploitation, mostraba todo aquello que estas comedias no habían podido mostrar (4).

Era necesario entonces implementar algún tipo de estrategia, dentro de las escasas posibilidades que brindaba el medio y la economía local, para recuperar público. Aries se vio obligada a repensar el modelo comercial que venía aplicando a sus distintas producciones y en particular el que utilizaba para explotar al dúo de cómicos que eran quienes aportaban la gran mayoría de sus ingresos por localidades. Decidieron entonces crear un nuevo perfil para los comediantes con la ayuda del director Enrique Carreras que fue contratado para dirigirlos. $\mathrm{Si}$ bien el cine que Carreras venía realizando estaba alejado del perfil que Olmedo y Porcel venían desarrollando en la pantalla grande, existían muchas similitudes en el modo en que el director trabajaba y el método de explotación de Aries: construyeron sagas alrededor de una dupla popular, filmaban rápido y barato, imitando el modelo de las quickies hollywoodenses, y entendían que la comedia era la forma más adecuada de llegar al mayor público posible.

Hasta el momento las películas de Olmedo y Porcel eran calificadas como aptas para mayores de 18 años y por lo tanto tenían un público restringido. Realizar una comedia familiar permitiría ampliar drásticamente el segmento de espectadores. El prolífico director tenía una amplia experiencia realizando este tipo de humor en el que venía trabajando desde los años cincuenta cuando con sus dos hermanos, Nicolás y Luis, fundaron Productora General Belgrano. A diferencia de las comedias de Aries, las películas producidas por los Carreras para la Belgrano se caracterizaron por proponer un modelo en el que imperaba el entretenimiento y el espectáculo. Construían sus filmes a partir de la conjunción de diversos elementos de la cultura popular-masiva que ya habían sido probados en otros ámbitos del mundo del espectáculo (Valdez, 2000). Luego de la disolución de la sociedad con sus hermanos, continuó filmando para otras productoras, y explotando el modelo que había creado para la Belgrano. Para comienzos de la década del ochenta sus comedias familiares eran garantía de éxito. Partiendo del modelo en el que venía trabajando hacía años, Carreras trasformó el perfil de la dupla y lo redirigió a un público familiar. La estrategia resultó ser un éxito en tanto que el primer filme que 
dirigió para Aries, Los fierecillos indomables (1982), logró llevar al cine a más de un millón de espectadores.

\section{Del humor picaresco al humor "apto para todo público"}

Las comedias protagonizadas por Olmedo y Porcel, entre 1973 y 1982, proponen un tipo de comicidad particular que puede ser encuadrada dentro de la denominada comedia picaresca. Este tipo de humor es el resultado de la conjunción de diversos elementos pertenecientes a distintas variantes del humor popular. Del humor costumbrista televisivo tomaron algunos de sus personajes estereotípicos a la vez que los espacios en donde transcurre gran parte de las historias -el interior del hogar, el barrio, las oficinas, los bares- y el lenguaje coloquial que utilizan los actores. Del teatro de revistas se valieron del humor subido de tono y los chistes procaces de los capo-cómicos revisteriles. Por último, se nutrieron de un conjunto de comedias que, a tono con la modernización del campo cultural y los cambios producidos en las costumbres y consumos de la clase media porteña durante los años sesenta, llevaron a la pantalla grande los conflictos sexuales de esta clase. De ellas tomaron algunos de los elementos de la fórmula que estas películas establecieron: un elenco de figuras conocidas, semi-desnudos femeninos y un humor centrado en lo sexual (Valdéz, 2005) (5).

Las comedias picarescas proponen, en general, el mismo tipo de historias. Narran como un conjunto de adultos masculinos de clase media que, aburridos de la rutina laboral y de la vida familiar, salen en busca de mujeres y terminan involucrándose en problemas fruto de una confusión y de su torpeza. Lo reidero se produce por medio de diversos recursos entre los que se destacan el humor verbal -por medio de chistes y juegos de palabras- y los gags visuales. Haciendo uso de la ambigüedad propia del lenguaje, los cómicos, subvierten los significados tradicionales de las palabras y crean asociaciones que están por fuera del uso común de las misma dando lugar a situaciones cómicas. Este tipo de asociaciones, a tono con el humor picaresco, giran en torno del sexo. De esta forma a lo largo de la saga proliferan los chistes y juegos de palabras en donde se utilizan distintos tipos de eufemismos para referirse a todo lo concerniente al sexo. El efecto cómico se produce a partir de la capacidad que tienen ambos cómicos de renovar o dar nuevos sentidos a las palabras que utilizamos en la vida cotidiana.

Los gags visuales también giran en torno de lo sexual. Su objetivo no es solo hacer reír al espectador sino también la mostración del cuerpo femenino. El gag tiene tres características básicas: la segmentación, la duración y la densidad. Es decir que está determinado por la forma en la que se articula lo que dura a la vez que lo que pesa el tiempo. El gag cobra forma 
por medio del uso de un tiempo con el fin de complicar el curso de las imágenes y hacer reír al espectador (Garín, 2014). Basta de mujeres (Hugo Sofovich, 1977) narra la historia de Alberto (Olmedo), un hombre reprimido sexualmente que no se anima a engañar a su esposa. En una escena de la película lo vemos llegar a un almacén. Allí el dueño lo deja solo con su mujer mientras se va a hacer el reparto de mercadería. La escena continúa con el personaje de Olmedo tomando coraje e intentando tener sexo con Pancha. La escena se va estirando por medio del montaje alterno que nos muestra los avances de este -impedido por la resistencia de ella, que va quedando desnuda, y los golpes que este se da con el mobiliario-, con los trayectos del marido haciendo el reparto. El remate del gag se da por medio del montaje. Al plano de las caras sorprendidas de Pancha y Olmedo, luego de escuchar la voz -fuera de campo- del marido que ha vuelto, le sigue un plano del cómico en su cama despertándose de un sueño.

De haber continuado con este tipo de comicidad, Carreras no hubiera podido ampliar el público del dúo. Por lo tanto, se vio obligado a transformar este humor con el fin de ganar nuevos espectadores y al mismo tiempo no perder aquellos que ya tenían. Para ello recondujo la comicidad hacia dos elementos que estaban presentes en las películas anteriores pero que no eran el atractivo principal: la comedia física y el enredo. Las películas pasaron entonces a narrar historias en donde la confusión de identidades y la coincidencia abusiva tienen un lugar central. La comicidad se produce al ver como los protagonistas se ven involucrados en situaciones cada vez más inverosímiles. Esto podemos observarlo en la premisa de la trilogía de los colimbas (6): dos adultos que, luego de vivir años en el exterior, vuelven al país y deben cumplir con el servicio militar obligatorio sino quieren ir a la cárcel por desertores. La comedia física, que en los filmes previos era patrimonio exclusivo de Porcel -organizada alrededor de su torpeza y de la exuberancia de su cuerpo- en esta nueva etapa se extendió también a Olmedo. Como dijimos anteriormente no se trataba sólo de atraer nuevos espectadores sino de mantener aquellos que los cómicos ya tenían. Para ello era necesario que los principales atractivos de los filmes picarescos, el sexo y los desnudos, siguieran estando presentes, aunque transformados. Para el público adulto, Olmedo y Porcel representaban la posibilidad de ir al cine a ver aquello que no se podía ver en otros ámbitos. Eran películas que proponían una visión de lo sexual alejada del discurso oficial de la dictadura (D'Antonio, 2015). El placer que producían este tipo de comedias estaba determinado por el disfrute que se da por medio la desviación de la norma (King, 2002). Lo sexual, por lo tanto, no podía desaparecer por completo porque hubiera implicado la pérdida de espectadores. Era necesario mantenerlo, pero morigerado. Otro elemento a tener en cuenta es que, estas comedias comienzan a filmarse casi en simultáneo con lo que se conoce como "destape", la mostración de todo aquello que 
había estado prohibido en dictadura -tanto en materia sexual como política- luego de la eliminación de la censura que propició el gobierno de Alfonsín. Debido al "destape", el sexo estaba presente en gran parte de la producción cultural del período (7). Estas películas, por lo tanto, no podían escapar a él. Para enfrentar esta situación, Carreras optó por convertir lo sexual en material apto para todo público.

Podemos observar esto en una escena de Los colimbas se divierten (Enrique Carreras, 1986). La escena comienza con un travelling lateral en el que vemos a las dos hijas del Coronel, vestidas con polleras cortas y paseando por una plaza hasta que ven unas hamacas y deciden subirse. El siguiente plano es de dos ancianos y un barrendero que observan lascivos a las dos mujeres. En una comedia picaresca el contraplano hubiera sido un plano frontal en donde fuera posible que el público viera la ropa interior de las actrices. Sin embargo, Carreras elige filmarlas de costado eludiendo mostrar la ropa interior. El director va realizando planos cada vez más cortos de las actrices que son intercalados con planos de los rostros extasiados de quienes observan. El remate del gag se da por medio de un plano conjunto de los dos ancianos siendo ensuciados por el barrendero que, obnubilado por lo que ve, yerra cuando debe depositar los residuos en el tacho de basura contiguo al banco. Este gag está construido de forma tal que funcione para el público más amplio posible. El público infanto-juvenil no ve la ropa interior y se divierte con la torpeza del barrendero. El público masculino adulto, por medio de la competencia adquirida viendo este tipo de películas, entiende el subtexto del gag aunque el disfrute de la visión de la ropa interior femenina quede impedido. Por medio de este procedimiento Carreras vuelve pacato a un chiste cuyo origen está en la picaresca de forma tal que las películas puedan ser calificadas como aptas para todo público.

\section{Machos, chantas y antihéroes}

El género es el resultado de una construcción social y cultural que da significado tanto a lo masculino como a lo femenino (Scott, 1999). Las producciones culturales, entre las que se encuentra el cine, construyen y reproducen roles de género atravesados por las representaciones hegemónicas presentes en el imaginario social de una época. Estas construcciones culturales imponen un tipo de rol apropiado para cada sexo (Scott, 1999). Siguiendo este planteo, entendemos que las comedias picarescas de Olmedo y Porcel dieron vida a personajes que reprodujeron estereotipos de género, tanto masculinos como femeninos, instalados en la cultura local. 
Como señalamos anteriormente, Aries buscaba realizar un cine redituable y para lograrlo decidió convertir a Olmedo y Porcel en dos estrellas cómicas taquilleras. Lo hizo aprovechando la extensa trayectoria en el mundo del espectáculo que ambos comediantes tenían antes de empezar a trabajar para esta productora. Como exponentes de la tercera fase del actor popular, ambos cómicos recurrieron a la tradición del actor nacional, para construir los personajes que crearon para la televisión y el teatro y que terminaron por delinear en el cine (Pellettieri, 2001). Partiendo del estereotipo del porteño chanta, muy presente en la cultura popular-masiva, cada uno desarrolló su propia variante. Olmedo encarnó un tipo de chanta particular, aquel que se presenta a sí mismo como la encarnación del "macho" pero que en el fondo es un cobarde. Su modo de actuación, siempre enérgico y furioso, ayudaba a darle carnadura a su creación, un hombre maduro siempre al borde de la excitación. Los gestos de su rostro -los guiños a su partenaire, sus sonrisas lascivas, sus manos incontrolablesgeneraban complicidad y empatía con el público (Fischer, 2009; Salzman, 2003). Porcel, por su parte, condenado a interpretar al mismo personaje debido a los estereotipos imperantes sobre su físico, es el torpe de la pareja (Casale, 2009). Oficia de cómplice de su amigo esperando una recompensa que nunca llega. Ambos, en su rol de chantas, recurrían a técnicas del actor popular como la improvisación, la morcilla y el furseo, con las cuales creaban grandes mentiras y situaciones de confusión con el fin de darse aires de importancia ante las mujeres o salir de grandes aprietos. Mientras que Olmedo cumplía el rol del galán fanfarrón, pero cuyas conquistas no son más que un cuento, Porcel interpretaba al que nunca logra concretar sus fantasías sexuales. Estos personajes tienen una imagen de sí mismos que reproduce características impuestas por el patriarcado para los hombres: tienen un apetito sexual voraz, se consideran seductores y triunfadores y creen que las mujeres son un trofeo. Están atravesados por una exigencia, por un deber ser -relacionado a la imposición de la virilidad masculina sobre la mujer- que forma parte del mandato patriarcal dominante (Bourdieu, 2000). Sin embargo, el devenir de los relatos hace que nunca puedan cumplir con su rol. Los pasos de comedia de las películas, se dan dentro de una tradición del humor local en donde la risa se produce a partir de la imposibilidad de los personajes de concretar sus deseos sexuales. La risa se da a partir de la impugnación de la masculinidad de los personajes. De esta forma, estas comedias refuerzan el estereotipo de género masculino al reírse de quien es incapaz de cumplirlo (8).

Dada la centralidad que tenía lo sexual en la construcción de estos personajes, Carreras se vio obligado a llevar a cabo una alteración de los mismos con el fin de ampliar el público de la dupla. Esta debía ser sutil para no perder la audiencia que ya tenían estos actores. Este director tenía amplia experiencia en crear y transformar el texto-estrella de diversas figuras del

Question, Vol. 1, N. 63, julio-septiembre 2019. ISSN 1669-6581

Instituto de Investigaciones en Comunicación | Facultad de Periodismo y Comunicación Social | Universidad Nacional de La Plata La Plata | Buenos Aires | Argentina

Página 9 de 19 
ámbito cinematográfico. Durante sus años bajo contrato con Argentina Sono Film, dedicó su filmografía a la depuración de los textos-estrella de figuras como Luis Sandrini y Libertad Lamarque (Anchou, 2005). Por lo tanto, este trabajo no representaba un gran desafío para Carreras. La tarea no pudo ser difícil debido a que tanto Olmedo como Porcel habían incursionado, con mayor o menor éxito, en el mundo del entretenimiento juvenil. Olmedo se había vuelto famoso entre los más jóvenes gracias a varios personajes que durante años interpretó en la pantalla chica: Joe Bazooka y el Capitán Piluso. Fue la interpretación de este segundo personaje, que incluso llegó al cine(9), el que le valió la fidelidad del público más joven. Porcel tuvo una relación menos cercana con este tipo de público, aunque también incursionó en el género en los sesenta cuando estuvo al frente del show televisivo Los sueños del gordo Porcel. Por otro lado, consideramos que, desde algunas de las comedias que protagonizó, existió desde Aries, un coqueteo con el público familiar con anterioridad a la llegada de Carreras. Un caso particular es el de la comedia Te rompo el rating (Hugo Sofovich, 1980) que logró, a diferencia de otras protagonizadas en solitario por Porcel, la clasificación apta para todo público, al abandonar el humor subido de tono y explotar un humor paródico a la vez que la comicidad física de su estrella cómica.

Teniendo en cuenta estos elementos podemos inferir que ambos actores, a pesar de estar fuertemente emparentados con la comedia para adultos también eran reconocidos y consumidos por un público infanto-juvenil. Por lo tanto era factible para Carreras y Aries recrear el perfil de ambos y realizar películas pensadas para toda la familia. Sus personajes, al retomar la comicidad de la producción infantil de ambos cómicos, se transformaron en dos amigos torpes. Los oficinistas grises obsesionados con el sexo se transformaron en uno dúo de antihéroes simpáticos y enamoradizos. El rol de género masculino también se transforma en estas películas. Se abandonó al chanta mujeriego por el antihéroe que logra conquistar a sus novias por medio del cortejo y de sus acciones "heroicas" y no por medio de la violencia del levante de las comedias picarescas. Podemos observar esta transformación, por ejemplo, en la construcción de los personajes protagónicos de Los extraterrestres (Enrique Carreras, 1983) y La galería del terror (Enrique Carreras, 1987). En la primera, el dúo de cómicos, logra conquistar el amor de las protagonistas cuando estas se dan cuenta que ellos traman un plan para salvar a un extraterrestre extraviado en la tierra. En la segunda, los protagonistas se proponen rescatar a dos mujeres que se encuentran bajo los efectos de la hipnosis del villano de la película. En estas películas ya no se celebra el estereotipo del macho conquistador, pero si se construye un nuevo rol en donde se refuerza la virilidad masculina. A pesar de la torpeza que caracteriza a estos anti héroes, son capaces de mostrarse viriles al actuar como 
protectores de los personajes femeninos al mismo tiempo que logran, por medio de sus acciones heroicas, conquistar su amor.

\section{Esposas, novias y amantes}

Estas películas no solo construyeron roles de género masculinos, sino también femeninos, al proponer modelos de mujer al servicio de la satisfacción de los deseos de los hombres. Si bien las representaciones femeninas son diversas es posible dividir a estos personajes en dos grupos. En el primero podemos englobar a aquellos que están relacionados al ámbito familiar: las esposas, las madres y las suegras. Estas mujeres son mostradas como las garantes de un hogar estable y armonioso al cuidar de sus hijos y de sus esposos. Al mismo tiempo se las retrata de forma negativa por medio de una puesta en escena que busca mostrarlas como mujeres poco atractivas y carentes de deseo sexual. La vida en familia aparece como carente de atractivo y por eso las aventuras fuera del hogar son la forma que encuentran los hombres de satisfacer sus deseos sexuales.

La representación del segundo grupo está armada de forma opuesta al primero (10). Aparecen convertidas por la puesta en escena en objetos sexuales por medio del uso de planos cortos de partes de su cuerpo -en particular de sus senos, sus traseros, e incluso sus labios-. Su cuerpo está para ser observado por los hombres de las historias y por el público masculino. A la vez son construidas como sujetos dramáticos con voluntad propia, desprejuiciados, decididos a la hora del sexo. Como mujeres independientes que se muestran a sí mismas y a la sociedad en general como autosuficientes. Son mujeres inteligentes que pueden resolver situaciones complejas en contraposición a los hombres que creen ser inteligentes, pero son incapaces de enfrentar cualquier situación. Mujeres cuya voluntad no se puede quebrantar y por lo tanto resultan poco convenientes como pareja estable para los hombres. Su rol es el de ser objeto de deseo de los hombres, el de ser amantes, pero nunca esposas. Las películas muestran que el modelo de mujer adecuado para los hombres es de la esposa que, a pesar de ser poco atractivas y carentes de libido, los esperan en sus casas dispuestas a perdonar infidelidades y cuidarlos. El disfrute del sexo está asociado a un tipo de mujer que no es compatible con la vida hogareña.

Las mujeres de las comedias "para toda la familia", en cambio, cumplen otro tipo de rol. Dado el conservadurismo de Carreras ya no hay lugar para mujeres como las del grupo mencionado en el párrafo anterior. Sin embargo, debido a que el público estaba acostumbrado a ver a los cómicos acompañados de mujeres bellas, era necesario que permanecieran en las historias. 
Para solucionar este problema, decidió llevar adelante una fusión entre los personajes del primer y segundo grupo haciendo que las vedettes interpretaran a los personajes femeninos positivos. Sin embargo, esta no fue la única modificación. Si con anterioridad los personajes interpretados por las vedettes eran de carácter fuerte y tenían un lugar claro en las historias, en las comedias "atp" pasaron a estar en segundo plano. La psicología de los personajes se desdibuja y aparecen como elementos decorativos de la narración. Ninguno de los personajes femeninos de esta nueva etapa tiene la fuerza de los de la etapa anterior.

Las decisiones que toma Carreras a la hora de retratar los cuerpos femeninos refuerzan el conservadurismo de su propuesta. Con el fin de que sus comedias fueran calificadas como aptas para todo público eliminó los desnudos femeninos. Sin embargo, para retratar los cuerpos de las actrices decidió recurrir al mismo tipo de puesta en escena que las comedias de los setenta. Es decir que en estas películas el cuerpo femenino también está concebido como un objeto a ser contemplado por los hombres. Al comienzo de El profesor punk (Enrique Carreras, 1988) vemos, encuadradas de la cintura para arriba, a un conjunto de adolescentes junto a su profesora, haciendo gimnasia en el patio de la escuela. Luego de una serie de planos de cada una de ellas pasamos a un plano de un profesor manejando. El plano siguiente es un plano general de las chicas y de la profesora, de espaldas y en el centro. Por medio del uso del zoom se encuadra el trasero de la profesora. A continuación se alternan una serie de planos del rostro sorprendido del profesor y de planos cada vez más cercanos del trasero de la profesora. La secuencia finaliza con un plano del profesor chocando su auto debido a la distracción que le produjo ver el cuerpo de la profesora. Aquí podemos observar como nuevamente la comicidad pasa por la torpeza de los personajes fruto de lo que provoca en un hombre un cuerpo femenino. Al perder su carnadura psicológica y estar presentes en la pantalla por medio de la fragmentación sexualizada de su cuerpo, los personajes femeninos se ven reducidas a ser nada más que el objeto de contemplación.

\section{Entretenimiento y espectacularización}

El cine familiar de Carreras se caracterizó siempre por apelar no solo a la comedia sino también al entretenimiento. El cine de entretenimiento familiar tiende a la contaminación con otros medios y expresiones artísticas como la radio, la revista teatral, la industria discográfica y la televisión. De ellos toma diversos elementos como ser fórmulas narrativas, personajes populares 0 actores identificados con alguna de las mencionadas expresiones. De esta forma, este cine se conforma como "un entramado narrativo heterogéneo y cambiante, del cual 
emerge como rasgo más específico, la permanencia de la figura del cómico como elemento estructurante y sostén del relato" (Paladino, 1994: 155). Las comedias familiares que Carreras realizó con Olmedo y Porcel recurren, en gran parte, a este modelo. Con el fin de ampliar público, el director apeló a la espectacularización incorporando diversos artistas populares, y sus rutinas, provenientes de otros medios. Es necesario tener en cuenta que la inclusión de situaciones espectaculares al interior de la trama no era ajena a las comedias picarescas que producía Aries. El público de Olmedo y Porcel estaba acostumbrado a que dentro de la película hubiera situaciones de este tipo. Sin embargo, estas se reducían a la presencia de un cuadro, que podía ser la interpretación de un cantante o un número musical de revistas. En cambio, en las comedias familiares estos números están presentes a lo largo de toda la película.

Dado que Carreras buscaba captar un público joven, decidió incorporar expresiones artísticas que apuntaran a esta porción de la audiencia. Recurrió tanto a la presencia de figuras de programas de televisión con alto rating como a la inclusión de solistas y grupos musicales populares entre niños y adolescentes. De esta forma podemos ver a gran parte del elenco de la telecomedia Mesa de noticias (11) en la trilogía de los colimbas. La popularidad de este show televisivo era tan grande que los protagónicos femeninos fueron otorgados a dos de las actrices más populares de ese programa (Cris Morena y Adriana Salgueiro). La presencia de estas figuras, que compartían afiche con las dos estrellas de la serie, aseguraba la afluencia masiva a las salas. Este estrategia resultó efectiva y logró que Los colimbas se divierten (1986) se convirtiera en la película más taquillera de todas las filmadas por la dupla (12). En este mismo sentido funciona la incorporación de momentos musicales interpretados por bandas nuevas de diversos géneros que apuntaban a un público joven. El dúo Pimpinela, que incursionaba en el género melódico, participó de dos películas. Los pericos, banda emergente del rock nacional -género que se convirtió en masivo en los años ochenta-, intervino en El profesor punk (Enrique Carreras, 1988), en donde es mostrada como una banda orientada al público adolescente. El objetivo de apelar a un público joven está presente incluso en la elección de algunos espacios en donde transcurren las películas. La galería del terror fue filmada en parte en el parque de diversiones Ital Park, el cual fue, hasta su cierre, un lugar de reunión para niños y adolescentes.

Un elemento característico del cine realizado en los cincuenta por Carreras es la parodia. Estas películas se caracterizaron por incluir en la trama un gran número de situaciones paródicas protagonizadas por distintos cómicos destacándose los números de fonomímica interpretados por Alfredo Barbieri. Si bien la parodia no era un elemento ajeno a las películas de Olmedo y Porcel, esta no tenía el lugar que ocupaba en la obra de Carreras ni tenía los mismos objetivos. La parodia es un recurso humorístico que implica la imitación o remedo de un estilo. Se 
caracteriza por recurrir a la exageración de las particularidades estilísticas de un texto. Parte de aquello que hace único a un estilo para producir una copia exacerbada que se burla del original (Jameson, 1999). La parodia puede tener un efecto satírico que busca criticar el objeto burlado. Puede ser utilizada como un vehículo para hacer comentarios sociales. También puede tener el efecto contrario, puede ser una celebración del objeto burlado, el reconocimiento del lugar que ocupa dentro del campo cultural (King, 2002).

Las parodias que se dan en las comedias de Olmedo y Porcel de los setenta se proponen impugnar el discurso que eleva a las producciones artísticas cultas y denosta el arte popular. En uno de los segmentos televisivos de Te rompo el rating (Hugo Sofovich, 1980) el personaje que interpreta Moria Casán entrevista a Alberto Olmedo que interpreta una parodia de sí mismo. Allí, Olmedo en un tono serio se muestra harto del humor popular y repite los clichés que la crítica construyó contra el humor revisteril. El remate de la situación se da cuando Olmedo confiesa que en el verano va a hacer teatro de revistas porque es lo único que convoca al público. El mismo sentido tiene la parodia de la interpretación del mundialmente conocido bolero de Ravel realizada por Jorge Donn para el filme Los unos y los otros (Claude Lelouch, 1981) incluída en Los fierecillos al ataque (Enrique Carreras, 1982). Olmedo y Porcel, desde una película que pertenece, de acuerdo a los parámetros de la crítica culta, a lo bajo se burlan de una película considerada prestigiosa por recurrir a la alta cultura para legitimarse como obra de arte.

A diferencia de estas, en las películas de Carreras, las imitaciones de cantantes $u$ otras figuras conocidas del mundo del entretenimiento, no tienen por objetivo la crítica sino que más bien funcionan como burlas amables y cariñosas. No tienen la intención de impugnar la obra de los burlados sino más bien reírse de alguno de los manierismos estilísticos de los objetos parodiados. Estas parodias, a su vez, sirven como vehículo para incluir dentro de las películas referencias a elementos de la cultura popular-masiva destinada a los más jóvenes. Así vemos desfilar por estas comedias, parodias del grupo musical infantil Parchís, del dúo cómico Chasman y Chirolita y del extraterrestre que protagonizó la película E.T., el extraterrestre (E.T. the Extra-Terrestrial, Steven Spielberg, 1982).

Estas no se resumían a la imitación de cantantes o figuras conocidas del ámbito del espectáculo. A partir de Sálvese quien pueda (1984), ya en democracia, Carreras introduce la parodia política. Si bien las imitaciones realizadas por Mario Sapag, Nito Artaza y Carlos Russo no se proponían criticar las medidas o las ideas de los políticos que imitaban sino más bien reírse de su modo de hablar, de sus latiguillos, de sus gestos, la inclusión de las mismas era una propuesta innovadora. A lo largo de su carrera cinematográfica Olmedo y Porcel no habían hecho referencia al mundo de la política. El cambio cultural que se dio durante la apertura 
democrática, fruto de la eliminación de la censura, permitió que el humor político comenzara a imponerse en los medios masivos (13). El director entendió que la inclusión de estas imitaciones, en particular las de Mario Sapag, podía resultar atractivo para un público adulto. La popularidad del imitador, producto de las imitaciones que realizaba en su programa televisivo Las mil y una de Sapag, resultaba un elemento clave para aumentar la recaudación. Esto se puede observar en la confección del afiche de Sálvese quien pueda. En la parte superior se pueden ver los nombres y las caricaturas de Olmedo y Porcel, las estrellas de la película. Más abajo fueron colocadas cuatro imágenes de las imitaciones más populares de Sapag (Raúl Alfonsín, Carlos Menem, Dante Caputo y Roberto Galán). La decisión de darle un lugar tan importante al imitador era da cuenta de que era pensado como un elemento convocante.

\section{Consideraciones finales}

Como señala Geoff King (2012) la comedia se transforma a medida que las sociedades cambian y los paradigmas sociales se modifican. Las demandas del público y las transformaciones al interior del campo cultural hacen necesario que las producciones culturales, y en particular la comedia, se adecúe a las nuevas exigencias con el fin de no perder público. En este sentido es que Aries se vio obligada a actualizar el perfil de Olmedo y Porcel para adecuarlo a las nuevas exigencias del campo cinematográfico. Para lograrlo fue fundamental la contratación de Enrique Carreras, el director que más éxito logró dentro de la comedia para toda la familia. El modelo propuesto por la productora y el director fue tan exitoso que terminó convirtiéndose en fórmula copiada por las dos productoras grandes que quedaban en pie en los ochenta. Este modelo fue el único atisbo industrial durante la década (Paladino, 1994).

Si bien el modelo que Carreras diseñó para los cómicos resultó, en general, exitoso eso no implicó que abandonaran por completo el ámbito de la comedia picaresca. Con la democracia ya instalada, y en medio del destape que se daba en los medios de comunicación, realizaron dos películas que retomaban el modelo anterior, Mirame la palomita (Enrique Carreras, 1985) y Atracción peculiar (Enrique Carreras, 1988). A pesar de que ese era el ámbito en el cual ambos cómicos se movían con mayor soltura ninguna de las películas logró tener el éxito que tuvieron los que filmaron en los setenta ni mucho menos el que tuvieron los del modelo Carreras. Las cosas habían cambiado y ya no era necesario ir al cine para ver lo que se podía ver en la televisión. El humor subido de tono que Porcel y Olmedo realizaban en la pantalla chica competía con el que proponían para la pantalla grande. La pelea la terminó ganando la 
televisión. La picaresca logró sobrevivir poco tiempo en la pantalla grande convirtiéndose en un género remanente cuyas últimas expresiones fueron realizadas para el mercado del video hogareño (14). Ninguno de los comediantes que, durante esta década, protagonizaron películas de este tipo logró construir un vínculo con el público como el que generaron Olmedo y Porcel.

Notas

(1) Producciones Rafael Cohen produjo, entre otras, Clínica con música (Francisco Guerrero, 1974) y Hay que parar la delantera (Rafael Cohen, 1977). Todo Show contrató a Gerardo Sofovich, como autor y director, luego de su alejamiento de Aries, para las comedias Las muñecas hacen ¡Pum! (1979) y La noche viene movida (1980). Rey films Cinematográfica realizó Hotel de señoritas (Enrique Dawi, 1979) y La guerra de los sostenes (Gerardo Sofovich, 1980).

(2) "Estos films no fueron en absoluto marginales en la industria cinematográfica local, ya que de un total de ciento noventa y dos películas realizadas y estrenadas comercialmente durante el autodenominado Proceso de Reorganización Nacional, treinta y dos de ellas o diecisiete por ciento del total, como quiera evaluarse, compartieron un universo simbólico con personajes prototípicos y un modo de narrar y de representar en imágenes al género y a la sexualidad" (D’Antonio, 2015: 914).

(3) A partir de la apertura y de la "liberalización" de la censura que comienza darse con el cambio de autoridades, tanto en la presidencia de la Nación como en el Ente de Calificación, los cineastas locales comienzan a producir un cine que se propone, todavía de forma solapada, criticar al gobierno de facto. Con la llegada de la democracia, el cine argentino comienza una revisión del proceso militar por medio de diversas propuestas que pueden ser divididas en dos grandes grupos. Aquellas que recurrieron a un modelo "realista afectivo", que apela a una puesta en escena tradicional y a la identificación emocional del espectador, y aquellos que abordaron el pasado desde una variante reflexiva, que busca interpelar al público por medio de una puesta en escena que reflexiona sobre la representación cinematográfica y evita la identificación emocional (Amado, 2009).

(4) Nos referimos a aquellas películas de bajo presupuesto que se caracterizan por explotar temas como el sexo, las drogas o la violencia de forma sensacionalista. Con el fin de la censura, las productoras tradicionales volcaron su interés a este tipo de cine al considerar que existía un público ávido por ver este tipo de producciones a las que no había podido acceder en 
dictadura (Getino, 1998). Podemos mencionar, entre otros, los filmes de Emilio Vieyra Todo a nada (1984), Correccional de mujeres (1985) y Sucedió en el internado (1986).

(5) Podemos mencionar, entre otras, a La cigarra no es un bicho (Daniel Tinayre, 1963), Hotel alojamiento (Fernando Ayala, 1966), Psexoanálisis (1968, Héctor Olivera) y El bulín (Ángel Acciaresi, 1969).

(6) Los colimbas se divierten (Enrique Carreras, 1986), Rambito y Rambón, primera misión (Enrique Carreras, 1986) y Los colimbas al ataque (Enrique Carreras, 1987).

(7) El destape sexual no se dio solo en el campo cinematográfico sino también en toda la cultura popular-masiva. Con la vuelta de la democracia se volvieron muy populares una serie de revistas -Libre, La semana, Shock, entre otras- que combinaban el abordaje sensacionalista de la actualidad con la presencia de desnudos femeninos en sus tapas. La publicidad también fue un ámbito en donde se dio este fenómeno. Se volvió frecuente el uso de modelos semi desnudas para vender productos de consumo masivo: jeans, televisores, etcétera.

(8) La virilidad no debe ser entendida solo en términos sexuales sino también como "aptitud para el combate y para el ejercicio de la violencia" (Bourdieu, 2000: 76). Al igual que sucede con la burla sobre la imposibilidad de concretar el acto sexual, estos personajes son ridiculizados por su cobardía, su falta de fuerza y su incapacidad física. La norma, el hombre viril, se refuerza por medio de la denigración sobre aquel que no es capaz de cumplir con el mandato patriarcal.

(9) Las aventuras del Capitán Piluso (en el castillo del terror) (Francis Lauric, 1983).

(10) Estos personajes fueron interpretados por actrices provenientes del mundo de la revista. Entre quienes más se destacaron en la interpretación de este tipo de papeles se encuentran Susana Giménez y Moria Casán.

(11) Mesa de noticias fue un programa cómico diario, con guiones de Juan Carlos Mesa, que logró convertirse en uno de los shows televisivos más exitoso de la década. Estuvo al aire entre 1983 y 1987.

(12) Los colimbas se divierten llevó 1.508 .100 espectadores. Dato tomado de las estadísticas provistas por los libros Cine Argentino en democracia. 1983/1993 y Más allá de la pantalla.

(13) A partir de la vuelta de la democracia el humor local, que hasta el momento -salvo excepciones como la revista Humor o programas, como Semanario insólito- se había dedicado al costumbrismo o la picaresca, comenzó a abordar otros temas, entre ellos la política. En Polémica en el bar, por ejemplo, Gerardo Sofovich llevó la disputa entre peronistas y radicales al ámbito del humor. Porcel y Juan Carlos Altavista, eran los peronistas, mientras que Santiago Bal encarnaba un radical alfonsinista. Otro caso es el de Mesa de noticias, que transcurría en 
la redacción de un noticiero, centraba su humor en la actualidad por lo que hacía referencias constantes a la política nacional (Ulanovsky, Itkin y Sirvén, 1999).

(14) Podemos mencionar, entre otras, Más loco que un crucero (Néstor Robles y Roberto Sena, 1989), Trolos, sordos y locas (Pablo Belini, 1991) y Maestro de pala (Emilio Vieyra, 1993).

\section{Bibliografía}

Amado, A. (2009). La imagen justa. Cine argentino y política (1980-2007). Buenos Aires: Colihue.

Anchou, G. (2005). El sueño industrial en emergencia. En España, C. (Dir.). Cine Argentino. Modernidad y Vanguardias. 1957/1983. Vol. II. Buenos Aires: Fondo Nacional de las Artes.

Bourdieu, P. (2000). La dominación masculina. Barcelona: Anagrama.

Casale, M. (2009). Jorge Porcel. En Pellettieri, O. (Dir.). Diccionario biográfico estético del actor en Buenos Aires. Volumen I: El actor popular, antecedentes y evolución. Buenos Aires: Galerna.

Ciria, A. (1996). Más allá de la pantalla. Cine argentino, historia y política. Buenos Aires: Ediciones de la Flor.

D’Antonio, D. (2015). Paradojas del género y la sexualidad en la filmografía durante la última dictadura militar argentina. Revista Estudios Feministas, 23(3), septiembre-diciembre, Universidade Federal de Santa Catarina, Brasil, pp. 913-93.

Fischer, P. (2009). Alberto Olmedo. En Pellettieri, O. (Dir.). Diccionario biográfico estético del actor en Buenos Aires. Volumen I: El actor popular, antecedentes y evolución. Buenos Aires: Galerna.

Garín, M. (2014). El gag visual. De Buster Keaton a Super Mario. Madrid: Cátedra.

Getino, O. (1998). Cine argentino. Entre lo posible y lo deseable. Buenos Aires: Ciccus.

Gociol, J. e Invernizzi, H. (2006). Cine y dictadura. Buenos Aires: Capital intelectual.

Jameson, F. (1999). El giro cultural. Buenos Aires: Manantial.

King, G. (2002). Film comedy. Nueva York: Wall Flower Press.

López, D. (2005). Erotismo y humor en Aries. Olmedo y Porcel. Noventa minutos de pura risa. En España, C. (Dir.). Cine Argentino. Modernidad y Vanguardias. 1957/1983. Vol. II. Buenos Aires: Fondo Nacional de las Artes. 
Paladino, D. (1994). El cine de entretenimiento. En España, C. (Dir.). Cine argentino en democracia. 1983/1993. Buenos Aires: Fondo Nacional de las Artes.

Pellettieri, O. (2001). En torno al actor nacional: el circo, el cómico italiano y el naturalismo. En Pellettieri, O. (Dir.). De Totó a Sandrini. Del cómico italiano al "actor nacional" argentino. Buenos Aires: Galerna/Instituto italiano de cultura de Buenos Aires.

Salzman, I. (2003). Alberto Olmedo o la gozosa infelicidad. En Pellettieri, O. (Dir.). De Eduardo De Filippo a Tita Merello. Del cómico italiano al "actor nacional" argentino (II). Buenos Aires: Galerna/Instituto italiano de cultura de Buenos Aires.

Scott, J. (1999). El género: una categoría útil para el análisis histórico. En Navarro, M. y Stimpson, C. (Comp.). Sexualidad, género y roles sexuales. Buenos Aires: Fondo de cultura económica.

Ulanovsky, C.; Itkin, S. y Sirvén, P. (1999). Estamos en el aire. Una historia de la televisión argentina. Buenos Aires: Planeta.

Valdéz, M. (2000). Productora General Belgrano. El formato chico, rápido y productivo. En España, C. (Dir.). Cine argentino. Industria y clasicismo. 1933/1956. Vol. I. Buenos Aires: Fondo Nacional de las Artes.

Valdéz, M. (2005). Fernando Ayala, cultor de la crónica y de la actualidad. En España, C. (Dir.). Cine Argentino. Modernidad y Vanguardias. 1957/1983. Vol. I. Buenos Aires: Fondo Nacional de las Artes.

Williams, R. (1981). Cultura. Sociología de la comunicación y del arte. Barcelona: Paidós. 